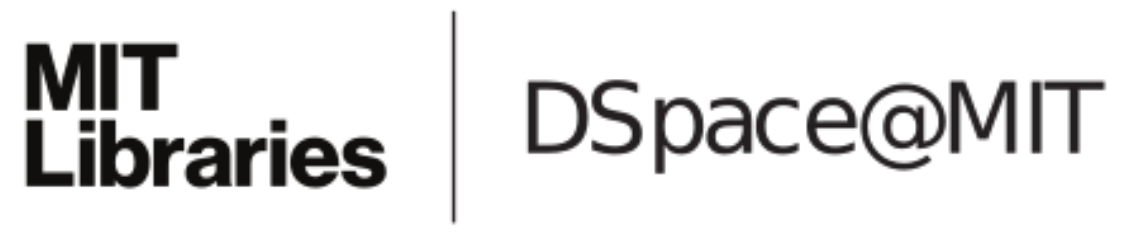

\author{
MIT Open Access Articles
}

Low-threshold terahertz quantum-cascade lasers with one-well injector operating up to $174 \mathrm{~K}$

The MIT Faculty has made this article openly available. Please share how this access benefits you. Your story matters.

Citation: Kumar, S., Qing Hu, and J.L. Reno. “Low-threshold Terahertz quantum-cascade lasers with one-well injector operating up to $174 \mathrm{~K}$." Lasers and Electro-Optics, 2009 and 2009 Conference on Quantum electronics and Laser Science Conference. CLEO/QELS 2009. Conference on. 2009. 1-2. (C2009 Institute of Electrical and Electronics Engineers.

Publisher: Institute of Electrical and Electronics Engineers

Persistent URL: http://hdl.handle.net/1721.1/59481

Version: Final published version: final published article, as it appeared in a journal, conference proceedings, or other formally published context

Terms of Use: Article is made available in accordance with the publisher's policy and may be subject to US copyright law. Please refer to the publisher's site for terms of use. 


\title{
Low-Threshold Terahertz Quantum-Cascade Lasers with One-Well Injector Operating up to $174 \mathrm{~K}$
}

\author{
Sushil Kumar, Qing Hu \\ Department of Electrical Engineering and Computer Science and Research Laboratory of Electronics, Massachusetts Institute of Technology, \\ Cambridge, MA 02139 \\ PH: 617-253-2431, FAX: 617-258-7864, email: sushil@mit.edu
}

John L. Reno

Sandia National Laboratories, Center of Integrated Nanotechnologies, MS 1303, Albuquerque, NM 87185-1303

\begin{abstract}
We report operation of $\nu \sim 2.7 \mathrm{THz}$ quantum-cascade lasers (QCLs) up to $174 \mathrm{~K}$. A new three-well active region, one-well injector scheme is utilized to lower the operating current densities. While the temperature performance of this design is comparable to that of the best published $\mathrm{THz}$ QCLs, lower operating current densities make this design a viable alternative.
\end{abstract}

(C) 2009 Optical Society of America

OCIS codes: (140.5965) Semiconductor lasers, quantum cascade; (140.3070) Infrared and far-infrared lasers

\section{Introduction}

Terahertz (THz) quantum-cascade lasers (QCLs) [1] have rapidly covered the frequency range of $1.2-5.0 \mathrm{THz}$ $(\lambda \sim 250-60 \mu \mathrm{m})$ [2]. They have already been demonstrated in applications such as imaging, spectroscopy, and as local oscillators in heterodyne receivers. There is a strong effort currently to increase their operating temperatures so that cryogenic operation may be avoided.

Currently the best temperature performance of $178 \mathrm{~K}$ is obtained by a variant of the original resonant-phonon design $[3,7]$, which utilizes a one-well injector, two-well active region scheme $[4,5]$. A one-well injector active region [6] limits the optical losses in the active region of a THz QCL due to the absence of intersubband absorption in the injector region where most of the electron population is located. Additionally, it affords superior injection selectivity for the resonant-tunneling transport in the cascaded structure thereby maximizing population inversion in the active region.

\section{Results}

(a) OWI202D-M1 band diagram

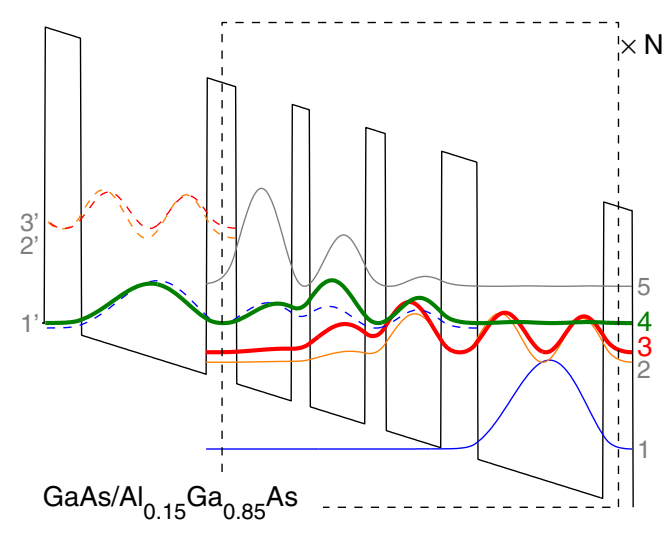

(b) Experimental results from a $150 \mu \mathrm{m} \times 2.07 \mathrm{~mm}$ ridge laser

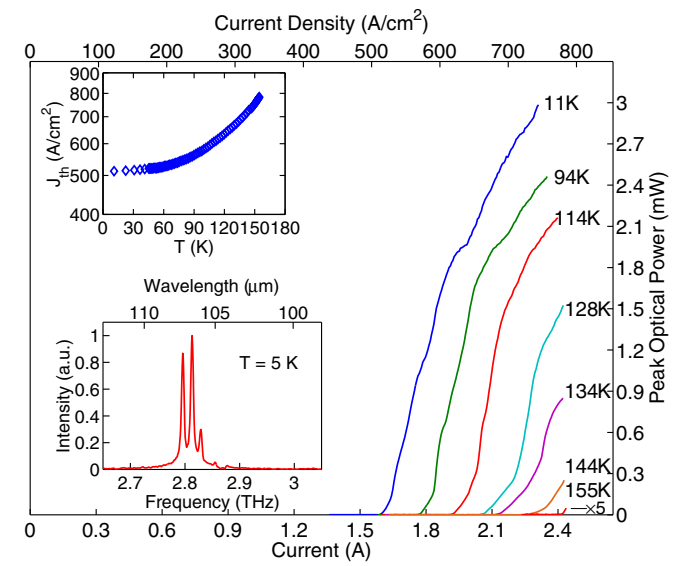

Fig. 1. (a) Conduction band diagram for a one-well injector, three-well active region that is similar to a previously published design [6]. The radiative transition is from $4 \rightarrow 3\left(\nu \approx E_{43} / h \approx 2.8 \mathrm{THz}\right)$ and $E_{21} \approx \hbar \omega_{\mathrm{LO}}$. (b) Experimental results from a metal-metal waveguide [7] ridge laser in pulsed operation. For this device $T_{\max } \sim 155 \mathrm{~K}$ and $J_{\mathrm{th}, 5 \mathrm{~K}} \sim 510 \mathrm{~A} / \mathrm{cm}^{2}$. 


\section{CThH4.pdf}

Figure 1 shows the conduction band diagram and experimental results from OWI202D-M1, a one-well injector, three-well active region design. This design is similar to that of the first published one-well injector design [6] but modified for a higher frequency operation. The key characteristic of this design is a three-well active region, which allows the $4 \rightarrow 3$ radiative transition to be made more diagonal and hence reduce the low-bias parasitic leakage current channels [6]. Therefore, the operating current densities in the structure are lowered. However, for this design, an upper parasitic level 5 exists in the active region, which gets populated with electrons at higher temperatures and hence lowers the amount of population inversion that could be obtained.

(a) OWI180E band diagram

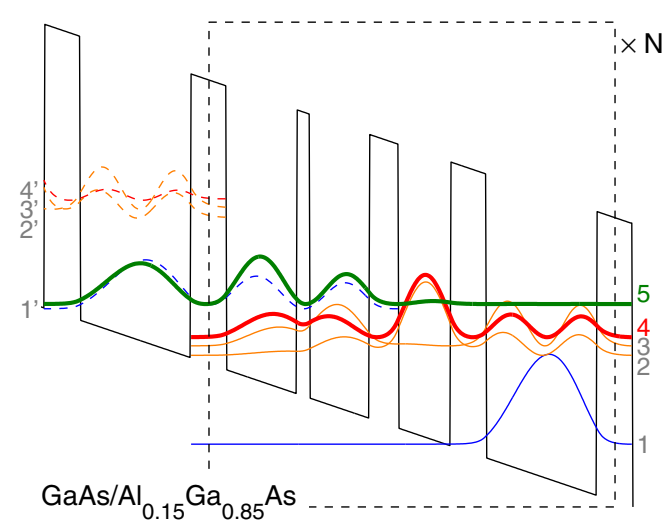

(b) Experimental results from a $100 \mu \mathrm{m} \times 2.54 \mathrm{~mm}$ ridge laser

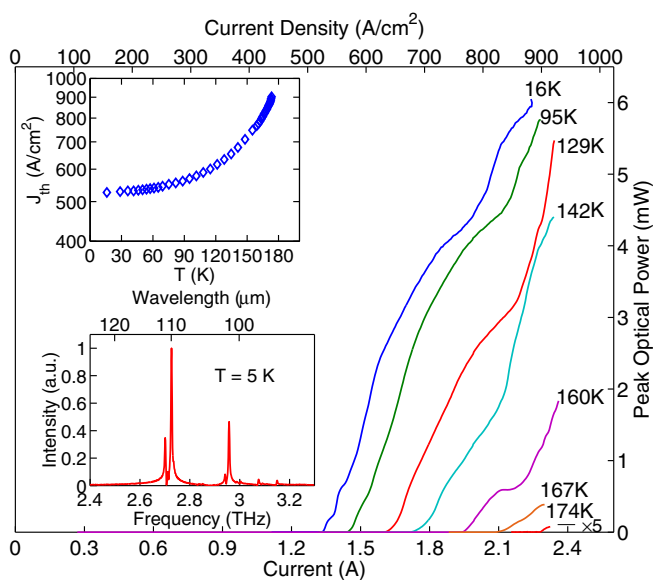

Fig. 2. (a) Conduction band diagram for a new one-well injector, three-well active region design. The radiative transition is from $5 \rightarrow 4$ $\left(\nu \approx E_{54} / h \approx 2.7 \mathrm{THz}\right.$ ) and $E_{21} \approx \hbar \omega_{\mathrm{LO}}$. (b) Experimental results from a metal-metal waveguide [7] ridge laser in pulsed operation. For this device $T_{\max } \sim 174 \mathrm{~K}$ and $J_{\mathrm{th}, 5 \mathrm{~K}} \sim 525 \mathrm{~A} / \mathrm{cm}^{2}$.

In figure 2, conduction band diagram and experimental results from a new design is presented. Superficially, this design looks similar to the previous one shown in Fig. 1, with one-well injector and three-well active region. However, in this structure, named OWI180E, the radiative transition takes place between the top two levels of the triplet states in the three-well active region. This eliminates the upper parasitic level 5 from the original design of Fig. 1 and hence achieves superior temperature performance.

The maximum operating temperature of $174 \mathrm{~K}$ for OWI180E (Fig. 2) is a validation of the advantage of this new design and it is comparable to the best published results for THz QCLs so far [5]. Additionally, its operating current density range of $\sim 500-900 \mathrm{~A} / \mathrm{cm}^{2}$ is significantly lower than the $800-1400 \mathrm{~A} / \mathrm{cm}^{2}$ range for the two-well active region design in Ref. [5] due to the additional well in its active region. Further optimization of the design will likely lead to even higher operating temperatures.

This work is supported by AFOSR, NASA, and NSF. Sandia is a multiprogram laboratory operated by Sandia Corporation, a Lockheed Martin Company, for the U.S. Department of Energy under Contract DE-AC04-94AL85000.

\section{References}

1. R. Köhler, A. Tredicucci, F. Beltram, H. E. Beere, E. H. Linfield, A. G. Davies, D. A. Ritchie, R. C. Iotti, and F. Rossi, “Terahertz semiconductor-heterostructure laser," Nature 417, 156 (2002).

2. B. S. Williams, "Terahertz quantum-cascade lasers," Nature Photonics 1, 517 (2007).

3. B. S. Williams, H. Callebaut, S. Kumar, Q. Hu, and J. L. Reno, "3.4-THz quantum cascade laser based on longitudinal-optical-phonon scattering for depopulation,” Appl. Phys. Lett. 82, 1015 (2003).

4. H. Luo, S. R. Laframboise, Z. R. Wasilewski, G. C. Aers, H. C. Liu, J. C. Cao, "Terahertz quantum-cascade lasers based on a three-well active module," Appl. Phys. Lett. 90, 041112 (2007).

5. M. A. Belkin, J. A. Fan, S. Hormoz, F. Capasso, S. Khanna, M. Lachab, A. G. Davies, and E. H. Linfield, "Terahertz quantum cascade lasers with copper metal-metal waveguides operating up to $178 \mathrm{~K}$," Opt. Express 16, 3242 (2008).

6. S. Kumar, B. S. Williams, , Q. Hu, and J. L. Reno, "1.9 THz quantum-cascade lasers with one-well injector," Appl. Phys. Lett. 88, 121123 (2006).

7. B. S. Williams, S. Kumar, Q. Hu, and J. L. Reno, "Operation of terahertz quantum-cascade lasers at $164 \mathrm{~K}$ in pulsed mode and at $117 \mathrm{~K}$ in continuous-wave mode," Opt. Express 13, 3331 (2005). 